\title{
New Tables of Howland's and Related Integrals
}

\author{
By C. W. Nelson
}

1. Introduction. In an earlier paper by C. B. Ling and the present author [1], values of the four integrals,

$$
\begin{array}{ll}
I_{k}=\frac{1}{2(k !)} \int_{0}^{\infty} \frac{w^{k} d w}{\sinh w \pm w}=\frac{2^{k}}{k !} \int_{0}^{\infty} \frac{x^{k} d x}{\sinh 2 x \pm 2 x}, & (k \geqq 1) \\
I_{k}{ }^{*}=\frac{1}{(k \geqq 3)} \\
I I_{k}=\frac{1}{2(k !)} \int_{0}^{\infty} \frac{w^{k} e^{-w} d w}{\sinh w \pm w}=\frac{2^{k}}{k !} \int_{0}^{\infty} \frac{x^{k} e^{-2 x} d x}{\sinh 2 x \pm 2 x}, & (k \geqq 1) \\
I I_{k}{ }^{*}=(k \geqq 3)
\end{array}
$$

were tabulated to 6D. These four integrals are called Howland's integrals because they first appeared in Howland's papers dealing with the stresses in a perforated strip $[2,3]$. In another paper, C. B. Ling has reproduced the $6 \mathrm{D}$ tables of Howland's integrals from [1] and added tables of other integrals derived from them [4].

2. Values of Howland's Integrals to $9 \mathrm{D}$. For most purposes, $6 \mathrm{D}$ tables of Howland's integrals are adequate. This is usually true in plane-stress problems of elasticity involving straight bars of rectangular cross-section, for example. However, the author has found that even in such problems the stresses are more easily evaluated in all regions of interest in the bar without resorting to contour integration if 9D rather than 6D tables of Howland's integrals are available. The 9D values of Howland's integrals given in Table 1 were computed by the author and have been checked by using the following checking formulas [1]:

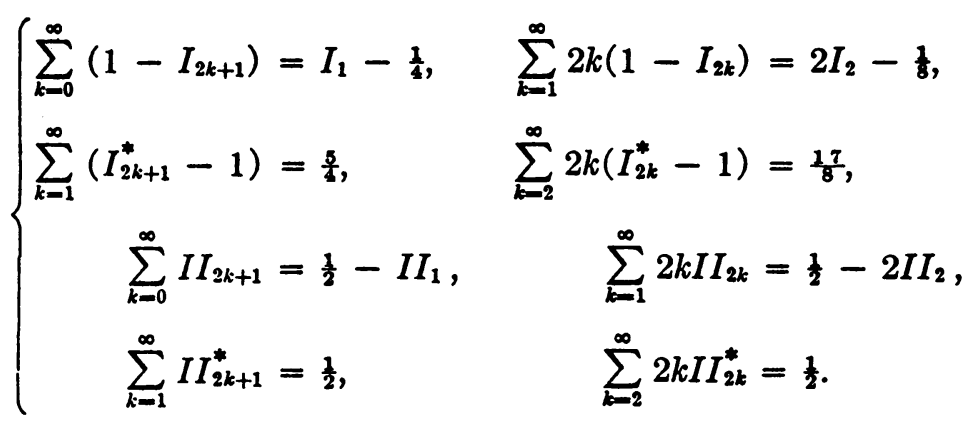

The method of computing the integrals is explained in [1] and this explanation will not be repeated here.

3. Values of $I_{2 k}, I_{2 k}^{*}$, and $\left[\begin{array}{l}2 \\ n\end{array}\right]$ to $18 \mathrm{D}$. Recently the author has encountered a need for still more precise values of some of the Howland's integrals. This occurs in the Hankel transform or Fourier-Bessel integral solutions $[5,6,7]$ for problems of elasticity involving axially symmetric loading of a thick plate of infinite radius,

Received June 6, 1960. 
NEW TABLES OF HOWLAND'S AND RELATED INTEGRALS

\section{TABLE 1}

Values of Howland's Integrals to $9 \mathrm{D}$

\begin{tabular}{|c|c|c|c|c|}
\hline$k$ & $I_{k}$ & $I_{k}^{*}$ & $I I_{k}$ & $I I_{k}^{*}$ \\
\hline 1 & $0.768 \quad 574 \quad 538$ & & $0.220 \quad 119 \quad 581$ & \\
\hline 2 & $\begin{array}{llll}0.767 & 847 & 439\end{array}$ & & 0.087927235 & \\
\hline 3 & $\begin{array}{llll}0.827 & 710 & 296\end{array}$ & $2.038 \quad 710 \quad 667$ & $0.043 \quad 347862$ & 0.460713719 \\
\hline 4 & $\begin{array}{llll}0.883 & 506 & 807\end{array}$ & 1.353294115 & $0.022 \quad 583004$ & $\begin{array}{lll}0.099 & 315 \quad 532\end{array}$ \\
\hline 5 & $0.925 \quad 475998$ & 1.156864366 & $\begin{array}{lll}0.011 & 923 & 473\end{array}$ & 0.032412690 \\
\hline 6 & $0.954 \quad 191562$ & 1.076729764 & $0.006 \quad 287972$ & 0.012616908 \\
\hline 7 & 0.972698993 & $\begin{array}{lll}1.039 & 251 \quad 312\end{array}$ & $\begin{array}{llll}0.003 & 295 & 013\end{array}$ & $0.005391 \quad 117$ \\
\hline 8 & $0.984124 \quad 180$ & $1.020 \quad 537600$ & $0.001713 \quad 298$ & 0.0024 .33000 \\
\hline 9 & $\begin{array}{llll}0.990 & 949 & 179\end{array}$ & $1.010870 \quad 147$ & $0.000884 \quad 147$ & $0.001 \quad 135997$ \\
\hline 10 & $0.994 \quad 922 \quad 440$ & $1.0057848+2$ & 0.000453215 & $0.000 \quad 542 \quad 202$ \\
\hline 11 & $\begin{array}{llll}0.997 & 188 & 575\end{array}$ & 1.003084774 & 0.000231010 & $0.000 \quad 262590$ \\
\hline 12 & $\begin{array}{llll}0.998 & 459 & 958\end{array}$ & $1.0016 \pm 4976$ & $\begin{array}{llll}0.000 & 117 & 209\end{array}$ & $\begin{array}{llll}0.000 & 128 & 431\end{array}$ \\
\hline 13 & $0.999 \quad 163823$ & 1.000876180 & 0.000059254 & 0.000063239 \\
\hline 14 & 0:999 549306 & 1.000465841 & $0.000 \quad 029870$ & $\begin{array}{llll}0.000 & 031 & 283\end{array}$ \\
\hline 15 & 0.999758559 & $\begin{array}{llll}1.000 & 247 & 139\end{array}$ & $0.000 \quad 015025$ & $0.000 \quad 015525$ \\
\hline 16 & 0.999871321 & $\begin{array}{llll}1.000 & 130 & 809\end{array}$ & $0.000 \quad 007546$ & $0.000 \quad 007 \quad 722$ \\
\hline 17 & $\begin{array}{llll}0.999 & 931 & 719\end{array}$ & 1.000069073 & 0.00000378 .5 & $0.000 \quad 003 \quad 847$ \\
\hline 18 & 0.999963903 & 1.000036390 & $0.000 \quad 001897$ & 0.000001919 \\
\hline 19 & 0.999980979 & $\begin{array}{llll}1.000 & 019 & 128\end{array}$ & $0.000 \quad 000950$ & $0.000 \quad 000958$ \\
\hline 20 & $0.999990 \quad 006$ & $1.000 \quad 010 \quad 034$ & $0.000000+76$ & 0.000000478 \\
\hline 21 & 0.999994762 & 1.000005252 & 0.000000238 & 0.000000239 \\
\hline 22 & 0.999997261 & 1.000002744 & 0.000000119 & $0.000 \quad 000119$ \\
\hline 23 & $0.999998 \quad 570$ & $\begin{array}{llll}1.000 & 001 & 431\end{array}$ & 0.000000060 & 0.000000060 \\
\hline 24 & 0.999999255 & 1.000000745 & $0.000000 \quad 030$ & 0.000000030 \\
\hline 25 & 0.999999613 & 1.000000388 & 0.000000015 & 0.000000015 \\
\hline 26 & 0.999999799 & 1.000000201 & 0.000000007 & 0.000000007 \\
\hline 27 & 0.999999896 & $\begin{array}{llll}1.000 & 000 & 104\end{array}$ & $0.000 \quad 000 \quad 004$ & $0.000000 \quad 004$ \\
\hline 28 & 0.999999946 & $1.000 \quad 000 \quad 054$ & $0.000 \quad 000 \quad 002$ & $0.000 \quad 000 \quad 002$ \\
\hline 29 & 0.999999972 & 1.000000028 & 0.000000001 & 0.000000001 \\
\hline 30 & 0.999999986 & 1.000000014 & 0.000000000 & 0.000000000 \\
\hline 31 & 0.999999993 & 1.000000007 & & \\
\hline 32 & 0.999999996 & 1.000000004 & & \\
\hline 33 & 0.999999998 & 1.000000002 & & \\
\hline 34 & 0.999999999 & 1.000000001 & & \\
\hline 35 & 0.999999999 & 1.000000001 & & \\
\hline 36 & 1.000000000 & 1.000000000 & & \\
\hline
\end{tabular}

where integrals such as

$$
F(\rho, \alpha)=\int_{0}^{\infty} \frac{\left(\sinh \frac{x}{2}+\frac{x}{2} \cosh \frac{x}{2}\right) J_{0}(\rho x) J_{1}(\alpha x) d x}{\alpha(\sinh x \pm x)}
$$

must be evaluated. In equation (4), $J_{0}(\rho x)$ and $J_{1}(\alpha x)$ are Bessel functions of order zero and unity, respectively. Sneddon $[5,6]$ describes an approximate method of evaluating such integrals. He and his associates appear to have treated only cases where the double sign in the denominator has the plus value, but, presumably, their 
method could be extended to cases where the double sign takes the minus value. Sneddon's approximate method does not involve the use of Howland's integrals.

For a limiting case of the integral in equation (4), namely $\alpha=0$ and double sign taken as plus, Sneddon found that his approximate method gave errors of the order of $1 \%$ for $\rho=0$ to $\frac{1}{2}$. However, the author found that Sneddon's approximate method applied to the integral in equation (4) gave an error of about $7 \%$ for $\rho=0, \alpha=1$, and double sign taken plus. Comparable errors in certain other integrals were obtained by the approximate method so that, in a certain thermal stress problem (radius of heated region equal to thickness of plate), the errors in normal stresses on the axis of the plate ranged up to $21.8 \%$ of the greatest normal stress occurring anywhere on the axis or $9.3 \%$ of the greatest normal stress occurring anywhere in the plate.

The author has felt that it is desirable to be able to obtain the values of integrals such as those considered in the foregoing two paragraphs with an accuracy better than that obtainable by Sneddon's approximate method. The more accurate values may at least be used to check a few values obtained by the approximate method in cases of doubt, and the availability of accurate values of the integrals occurring in thick-plate problems may cven be found essential in the extension of the Hankel transform method to problems not yet considered. The author first attempted to evaluate the stresiess in a thick-plate problem [7] with the aid of the $9 \mathrm{D}$ values of Howland's given in Table 1 and found that only a very limited range of values of the parameters $\rho$ and $\alpha$ in integrals such as that of equation (4) could be successfully dealt with. For this reason, the $18 \mathrm{D}$ values of two of the four Howland's integrals, $I_{k}$ and $I_{k}{ }^{*}$, for even integral $k$, were computed. These are given in Table 2 and discussed further in the following. Green and Willmore [9] encountered integrals similar to those discussed in the present paper except that theirs contained only one Bessel function. They used Howland's integrals for the simpler integrals they had to evaluate and Sneddon's approximate method for the rest. Apparently the Fourier-Bessel integral method was first applied to thick plate problems by Lamb [10], who made no attempt to evaluate the integrals. Dougall [11] proposed that integrals such as the example in equation (4), but containing only one Bessel function, be cvaluated by contour integration, but apparently no one has cared to perform the task involved which appears to be considerable even though the roots of $\sinh z \pm z=0$ are known.

If the integral taken as an example in equation (4) is expressed as a series of Howland integrals by expanding the numerator of the integrand in powers of $x$, only even powers of $x$ will occur in this expansion. Thus the integral can be evaluated if adequate values of $I_{k}$ or $I_{k}{ }^{*}$ are available for even integral $k$, and if the series converges or can somehow be summed. From a consideration of various loading conditions of a thick plate, it appears to the author that as long as the axiallysymmetric loading of the plate consists only of boundary loads on the plane faces (i.e. no body forces), all other integrals needed can also be evaluated from tables of $I_{k}$ and $I_{k}{ }^{*}$ for even integral $k$. Accordingly, the values of $I_{k}$ and $I_{k}{ }^{*}$ given to $18 \mathrm{D}$ in Table 2 are believed to be the only Howland integrals needed in a fairly broad class of thick-plate problems. Again the reader is referred to [1] for the general method of computing the integrals in Table 2. However, it should be stated here that the method depends on the basic equation 
TABLE 2

Values of the Howland Integrals $I_{2 k}$ and $I_{2 k}^{*}$ to $18 \mathrm{D}$

\begin{tabular}{|c|c|c|}
\hline$k$ & $I_{k}$ & $I_{k^{*}}$ \\
\hline 2 & $\begin{array}{llllll}0.767 & 847 & 439 & 133 & 919 & 047\end{array}$ & \\
\hline 4 & $\begin{array}{llllll}0.883 & 506 & 806 & 508 & 692 & 590\end{array}$ & $\begin{array}{llllll}1.353 & 294 & 115 & 170 & 484 & 009\end{array}$ \\
\hline 6 & $\begin{array}{llllll}0.954 & 191 & 561 & 826 & 139 & 064\end{array}$ & $1.076729763 \quad 674 \quad 217 \quad 127$ \\
\hline 8 & $\begin{array}{lllllll}0.984 & 124 & 180 & 148 & 424 & 614\end{array}$ & 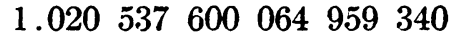 \\
\hline 10 & $\begin{array}{llllll}0.994 & 922 & 439 & 853 & 445 & 374\end{array}$ & 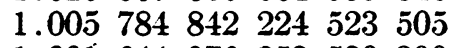 \\
\hline 12 & $\begin{array}{llllll}0.998 & 459 & 957 & 947 & 832 & 383\end{array}$ & 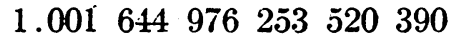 \\
\hline 14 & $\begin{array}{llllll}0.999 & 549 & 305 & 562 & 626 & 177\end{array}$ & $\begin{array}{llllll}1.000 & 465 & 841 & 012 & 174 & 418\end{array}$ \\
\hline 16 & $\begin{array}{lllllll}0.999 & 871 & 321 & 426 & 371 & 778\end{array}$ & 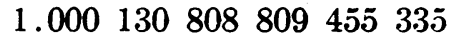 \\
\hline 18 & $\begin{array}{llllll}0.999 & 963 & 903 & 069 & 165 & 323\end{array}$ & $1.000 \quad 036 \quad 389774 \quad 380 \quad 024$ \\
\hline 20 & $\begin{array}{llllll}0.999 & 990 & 005 & 851 & 207 & 354\end{array}$ & $\begin{array}{llllll}1.000 & 010 & 033 & 628 & 030 & 387\end{array}$ \\
\hline 22 & $\begin{array}{llllll}0.999 & 997 & 260 & 778 & 826 & 414\end{array}$ & $1.000 \quad 00274445 \overline{5} 935026$ \\
\hline 24 & $\begin{array}{llllll}0.999 & 999 & 255 & 282 & 148 & 058\end{array}$ & 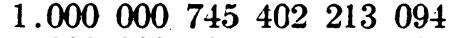 \\
\hline 26 & $\begin{array}{llllll}0.999 & 999 & 798 & 878 & 365 & 743\end{array}$ & 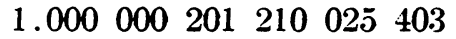 \\
\hline 28 & $0.999 \quad 999 \quad 945 \quad 988927 \quad 609$ & $1.000 \quad 000 \quad 054022369865$ \\
\hline 30 & $\begin{array}{llllll}0.999 & 999 & 985 & 565 & 214 & 614\end{array}$ & $1.000000014+36216216$ \\
\hline 32 & $\begin{array}{lllllll}0.999 & 999 & 996 & 158 & 384 & 196\end{array}$ & 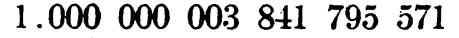 \\
\hline 34 & $\begin{array}{llllll}0.999 & 999 & 998 & 981 & 377 & 142\end{array}$ & 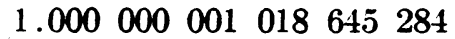 \\
\hline 36 & $0.999999999 \cdot 730790958$ & $1.000000 \quad 000269211822$ \\
\hline 38 & $\begin{array}{lllllll}0.999 & 999 & 999 & 929 & 059 & 585\end{array}$ & $\begin{array}{llllll}1.000 & 000 & 000 & 070 & 940 & 758\end{array}$ \\
\hline 40 & $\begin{array}{llllll}0.999 & 999 & 999 & 981 & 355 & 380\end{array}$ & 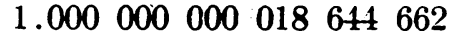 \\
\hline 42 & $\begin{array}{lllllll}0.999 & 999 & 999 & 995 & 111 & 469\end{array}$ & $1.000 \quad 000 \quad 000 \quad 004888537$ \\
\hline 44 & $\begin{array}{llllll}0.999 & 999 & 999 & 998 & 721 & 023\end{array}$ & 1.000000000001278977 \\
\hline 46 & $\begin{array}{lllllll}0.999 & 999 & 999 & 999 & 666 & 045\end{array}$ & $1.000000 \quad 000 \quad 000333955$ \\
\hline 48 & $\begin{array}{llllll}0.999 & 999 & 999 & 999 & 912 & 959\end{array}$ & 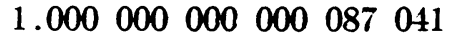 \\
\hline 50 & 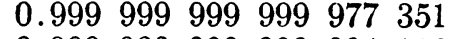 & 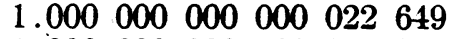 \\
\hline 52 & 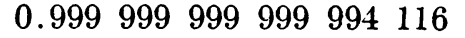 & 1.000000000000005884 \\
\hline 54 & $\begin{array}{llllll}0.999 & 999 & 999 & 999 & 998 & 473\end{array}$ & 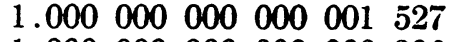 \\
\hline 56 & $\begin{array}{llllll}0.999 & 999 & 999 & 999 & 999 & 604\end{array}$ & $1.000000 \quad 000 \quad 000000396$ \\
\hline 58 & 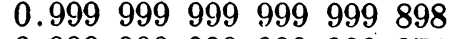 & 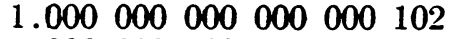 \\
\hline 60 & 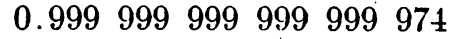 & 1.000000000000000026 \\
\hline 62 & 0.999999999999999993 & 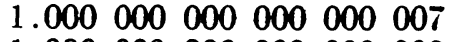 \\
\hline 64 & 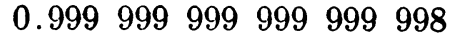 & 1.000000000000000002 \\
\hline 66 & 1.000000000000000000 & 1.000000000000000000 \\
\hline
\end{tabular}

$$
I_{k} I_{k}=\sum_{n=1}^{\infty}(\mp 1)^{n+1}\left[\begin{array}{l}
k \\
n
\end{array}\right]
$$

where

$$
\left[\begin{array}{l}
k \\
n
\end{array}\right]=\frac{1}{2(k !)} \int_{0}^{\infty} \frac{x^{n+k-1} d x}{\sinh ^{n} x}
$$

and that the values in Table 2 have been checked by using the second and fourth of equations (3). When these checks were first applied, errors were indicated. To eliminate these errors, they had to be located and this was facilitated by applying another checking formula $\dagger$

† For $n=1$, use

$$
\sum_{m=1}^{\infty}\left(\left[\begin{array}{c}
2 m \\
1
\end{array}\right]-1\right)=\frac{3}{4}-\ln 2
$$




$$
\sum_{m=1}^{\infty} \frac{2 m}{2 m+1}\left[\begin{array}{c}
2 m \\
n
\end{array}\right]=\frac{1}{2(n-1)}, \quad n=2,3,4, \cdots
$$

Equation (7) is obtained by writing the series of integrals represented by the left member of the equation, interchanging the order of summation and integration, performing the summation which requires merely recognition of the Maclaurin expansion of $\cosh x-\frac{\sinh x}{x}$ and then performing the evaluation of the resulting elementary integral as follows:

(8) $\frac{1}{2} \int_{0}^{\infty} \frac{x^{n-2}(x \cosh x-\sinh x) d x}{\sinh ^{n} x}=-\left.\frac{x^{n-1}}{2(n-1) \sinh ^{n-1} x}\right|_{0} ^{\infty}=\frac{1}{2(n-1)}$.

TABLE 3

Values of $\left[\begin{array}{l}2 \\ n\end{array}\right]$ to $18 \mathrm{D}$

\begin{tabular}{|c|c|c|c|}
\hline$n$ & {$\left[\begin{array}{l}2 \\
n\end{array}\right]$} & $n$ & {$\left[\begin{array}{l}2 \\
n\end{array}\right]$} \\
\hline 1 & $\begin{array}{llllll}1.051 & 799 & 790 & 264 & 645 & 000\end{array}$ & 21 & $\begin{array}{llllll}0.036 & 396 & 239 & 976 & 639 & 766\end{array}$ \\
\hline 2 & $\begin{array}{lllllll}0.45 & 771 & 338 & 684 & 847 & 857\end{array}$ & 22 & $\begin{array}{llllll}0.034 & 712 & 213 & 240 & 700 & 944\end{array}$ \\
\hline 3 & $\begin{array}{lllllll}0.283 & 656 & 164 & 817 & 032 & 302\end{array}$ & 23 & $\begin{array}{lllllll}0.033 & 177 & 094 & 523 & 417 & 174\end{array}$ \\
\hline 4 & $0.206 \quad 411 \quad 435 \quad 020 \quad 280449$ & 24 & $\begin{array}{llllll}0.031 & 771 & 973 & 852 & 978 & 737\end{array}$ \\
\hline 5 & $\begin{array}{llllll}0.162 & 091 & 502 & 769 & 567 & 468\end{array}$ & 25 & $\begin{array}{lllllll}0.030 & 481 & 012 & 454 & 106 & 163\end{array}$ \\
\hline 6 & $\begin{array}{llllll}0.133 & 389 & 997 & 047 & 394 & 398\end{array}$ & 26 & 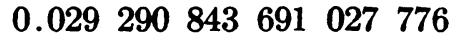 \\
\hline 7 & $\begin{array}{llllll}0.113 & 302 & 756 & 992 & 243 & 931\end{array}$ & 27 & $\begin{array}{llllll}0.028 & 190 & 108 & 942 & 707 & 765\end{array}$ \\
\hline 8 & $0.098+63 \quad 515074 \quad 533 \quad 508$ & 28 & $\begin{array}{lllllll}0.027 & 169 & 094 & 240 & 899 & 480\end{array}$ \\
\hline 9 & $\begin{array}{lllllll}0.087 & 055 & 830 & 293 & 630 & 464\end{array}$ & 29 & $\begin{array}{llllll}0.026 & 219 & 443 & 043 & 962 & 235\end{array}$ \\
\hline 10 & $\begin{array}{lllllll}0.078 & 014 & 012 & 373 & 164 & 903\end{array}$ & 30 & $\begin{array}{lllllll}0.025 & 333 & 927 & 165 & 280 & 539\end{array}$ \\
\hline 11 & $\begin{array}{lllllll}0.070 & 671 & 880 & 431 & 666 & 952\end{array}$ & 31 & $\begin{array}{llllll}0.024 & 506 & 262 & 569 & 448 & 302\end{array}$ \\
\hline 12 & $0.06(+4591 \quad 720 \quad 775032 \quad 384$ & 32 & $\begin{array}{lllllll}0.023 & 730 & 960 & 108 & 696 & 094\end{array}$ \\
\hline 13 & $\begin{array}{llllll}0.039 & 474 & 138 & 718 & 298 & 180\end{array}$ & 33 & $0.023003 \quad 203705225661$ \\
\hline 14 & $\begin{array}{llllll}0.055 & 107 & 451 & 486 & 079 & 519\end{array}$ & 34 & $\begin{array}{lllllll}0.022 & 318 & 750 & 267 & 406 & 497\end{array}$ \\
\hline 15 & $\begin{array}{lllllll}0.051 & 337 & 774 & 971 & 088 & 869\end{array}$ & 35 & $\begin{array}{llllll}0.021 & 673 & 846 & 947 & 047 & 716\end{array}$ \\
\hline 16 & $\begin{array}{lllllll}0.048 & 050 & 565 & 748 & 631 & 05 \overline{7}\end{array}$ & 36 & $\begin{array}{llllll}0.021 & 065 & 162 & 331 & 082 & 628\end{array}$ \\
\hline 17 & $\begin{array}{llllll}0.045 & 158 & 809 & 284 & 589 & 149\end{array}$ & 37 & 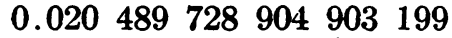 \\
\hline 18 & $\begin{array}{llllll}0.0+2 & 595 & 221 & 342 & 283 & 185\end{array}$ & 38 & $0.019944894690604 \quad 315$ \\
\hline 19 & $\begin{array}{lllllll}0.040 & 306 & 957 & 521 & 379 & 715\end{array}$ & 39 & $\begin{array}{llllll}0.019 & 428 & 282 & 397 & 575 & 541\end{array}$ \\
\hline 20 & $\begin{array}{llllll}0.038 & 251 & 937 & 970 & 666 & 201\end{array}$ & 40 & $\begin{array}{lllllll}0.018 & 937 & 754 & 758 & 470 & 797\end{array}$ \\
\hline
\end{tabular}

TABLE 4

Values of $\int_{0}^{\infty} \frac{x J_{1}(\rho x) d x}{\sinh x+x}$

\begin{tabular}{l|l}
\hline$\rho$ & $\int_{0}^{\infty} \frac{x J_{1}(a x) d x}{\sinh x+x}$ \\
\hline 0 & 0 \\
1 & 0.471 .282 \\
2 & 0.250403 \\
3 & 0.166664 \\
4 & 0.125000 \\
5 & 0.100000 \\
\hline
\end{tabular}


The values of $\left[\begin{array}{l}2 \\ n\end{array}\right]$ are recorded in Table 3 , since they are the starting point for obtaining $I_{k}$ and $I_{k}{ }^{*}$, and because they may be needed as in the example leading to Table 4 in the following. It was not felt necessary to include values of $\left[\begin{array}{l}m \\ n\end{array}\right]$ for $m=4,6,8, \cdots$ because, at worst, only a few such values might be needed by a reader, and these can be computed from Table 3 by using equation (16) given in the following.

4. Application of Howland's Integrals in Evaluating Related Integrals. Procedures for evaluating integrals such as those in equation (4) for moderate values of $\rho$ and $\alpha$, say for $\rho$ and $\alpha$ each less than unity, have been amply discussed in connection with similar integrals treated in references [2], [3], [4] and [7]. If either $\rho$ or $\alpha$ (or both) should be considerably greater than unity in integrals such as those of equation (4), some special study of the integral in question is usually required and an effort should be made to determine some simple expression which the value of the integral approaches asymptotically for large values of the parameter or parameters. Usually this can be done by considering the physical problem in which the integral arose and by examining the known approximate solution for a limiting case of the problem. For example, suppose the integral $\int_{0}^{\infty} \frac{x J_{1}(\rho x) d x}{\sinh x+x}$ is to be evaluated for a series of values of $\rho$ covering the range $0 \leqq \rho<\infty$. The integral arises in a three-dimensional elasticity problem involving axially symmetric loads on a thick plate. By considering a limiting case of the physical problem or by other methods, it can be shown that

$$
\int_{0}^{\infty} \frac{x J_{1}(\rho x) d x}{\sinh x+x} \approx \frac{1}{2 \rho}
$$

for large $\rho$.

Thus the range of values of $\rho$ which must be considered is reduced to the range from zero to the lowest value at which equation (9) gives the result with sufficient accuracy. The integral in question may be expressed as a series of integrals in the form

$$
\int_{0}^{\infty} \frac{x J_{1}(\rho x) d x}{\sinh x+x}=\sum_{n=1}^{\infty}(-1)^{n+1} \int_{0}^{\infty} \frac{x^{n} J_{1}(\rho x) d x}{\sinh ^{n} x}
$$

where the integrals in the right member may be evaluated by contour integration following the method described for a similar integral in [8]. For example, the first two integrals required are

$$
\begin{aligned}
& \int_{0}^{\infty} \frac{x J_{1}(\rho x) d x}{\sinh x}= \frac{1}{\rho}-2 \pi\left[\kappa_{1}(\pi \rho)-2 \kappa_{1}(2 \pi \rho)+3 \kappa_{1}(3 \pi \rho)-\cdots\right] \\
& \int_{0}^{\infty} \frac{x^{2} J_{1}(\rho x) d x}{\sinh ^{2} x}=\frac{1}{\rho}+2 \pi\left[\kappa_{1}(\pi \rho)+2 \kappa_{1}(2 \pi \rho)+3 \kappa_{1}(3 \pi \rho)+\cdots\right] \\
& \quad-2 \pi^{2}{ }^{2}\left[\kappa_{0}(\pi \rho)+4 \kappa_{0}(2 \pi \rho)+9 \kappa_{0}(3 \pi \rho)+\cdots\right]
\end{aligned}
$$

where $\kappa_{0}(x)$ and $\kappa_{1}(x)$ are modified Bessel functions of the second kind of order zero and one respectively.

By evaluating the first four integrals and applying an Euler transformation to 
the resulting alternating series in equation (10), the values of the left member of equation (10) for $\rho=4$ and $\rho=5$ were found to be as given in Table 4 . The entries in Table 4 were completed as follows. For $\rho=0$ and $\rho=1$, the integral was evaluated from

$$
\int_{0}^{\infty} \frac{x J_{1}(\rho x) d x}{\sinh x+x}=2 \rho I_{2}-2 \cdot \frac{3}{2} \rho^{3} I_{4}+2 \cdot \frac{3 \cdot 5}{2 \cdot 4} \rho^{5} I_{6}-\cdots
$$

For $\rho=2$ and $\rho=3$, a Kummer transformation was applied to equation (13) so as to obtain

$$
\int_{0}^{\infty} \frac{x J_{1}(\rho x) d x}{\sinh x+x}=\sum_{n=1}^{4}(-1)^{n+1} \int_{0}^{\infty} \frac{x^{n} J_{1}(\rho x) d x}{\sinh ^{n} x}+\text { Remainder Series }
$$

where

$$
\begin{aligned}
\text { Remainder Series }=2 \rho\left\{I_{2}-\sum_{n=1}^{4}(-1)^{n+1}\left[\begin{array}{l}
2 \\
n
\end{array}\right]\right\} & \\
& -2 \cdot \frac{3}{2} \rho^{3}\left\{I_{4}-\sum_{n=1}^{4}(-1)^{n+1}\left[\begin{array}{l}
4 \\
n
\end{array}\right]\right\}+\cdots
\end{aligned}
$$

The remainder series converges for $\rho<5$ but the convergence is, of course, very slow as $\rho$ approuches 5 and, even for $\rho=2$ and $\rho=3$, it is best to speed the convergence by applying an Euler transformation. To evaluate the series in equation (15), it is necessary to use Table 2 , Table 3 , and the equation

$$
\left[\begin{array}{l}
m \\
n
\end{array}\right]=\frac{1}{(m-1) m}\left\{\frac{(n+m-2)(n+m-1)}{n^{2}}\left[\begin{array}{c}
m-2 \\
n
\end{array}\right]\right.
$$

$$
\left.-\frac{(n+1)}{n}\left[\begin{array}{l}
m-2 \\
n+2
\end{array}\right]\right\}
$$

which is equivalent to the first of equations (4) in reference [1].

5. Acknowledgments. Except for Table 4, the tables presented in this paper were computed while the author was employed as Associate Professor of Mechanics and Design, University of California, Berkeley, California, prior to June 30, 1959.

Applied Physics Laboratory

GPI Development Laboratory

International Business Machines Corporation

Endicott, New York

1. C. B. Ling \& C. W. Nelson, "On evaluation of Howland's integrals," Annals of Academia Sinica, Taiwan, China, v. 2, part 2, 1955, p. 45-50.

2. R. C. J. HOWLAND. "On the stresses in the neighborhood of a circular hole in a strip under tension," Philos. Trans., Roy. Soc. London, Ser. A, v. 229, 1930, p. 49-86.

3. R. C. J. Howland \& A. S. STEvenson, "Biharmonic analysis in a perforated strip," Philos. Trans. Roy. Soc. London, Ser. A, v. 232, 1934, p. 155-222.

4. C. B. LiNG, "Tables of values of 16 integrals of algebraic-hyperbolic type," MTAC, v. 11,1957 , p. $160-166$.

5. I. N. SNEdDox, Fourier Transforms, McGraw-Hill, New York, 1951, p. 468-480.

6. I. N. SNEDDON, "The elastic stresses produced in a thick plate by the application of pressure to its free surfaces," Prọc., Cambridge Philos. Soc., v. 42, 1946, p. 260-271.

7. C. W. N.ELSON, "Thermal stresses in a thick plate owing to variation of temperature with radial position," to appear in $J$. A ppl. II $f c h$.

8. G. N. WATson, A Treatise on the Theory of Bessel Functions, Second Edition, Cambridge University Press, Cambridge, 1952, p. 427.

9. A. E. GreEN \& T. J. Willurore. "Three-dimensional stress systems in isotropic plates, II," Proc. Roy. Soc. London, Ser. A, v. 193, 1948, p. 229-248. 284.

10. H. LAMB, "On Boussinesq's problem," Proc. London Math. Soc., v. 34, 1902, p. 276-

11. J. Dougall, "An analytical theory of the equilibrium of an isotropic elastic plate," Trans. Roy. Soc. Edinburgh, v. 41, 1904, p. 129-228. 